\title{
Representações sociais de cristão e mídia religiosa de massa: propagação, difusão e propaganda no discurso de Edir Macedo
}

\author{
Social representations of christian and population religious midea: spread, difusion \\ and adivertising in Edir Macedo' speech
}

\author{
Diemerson Saquetto ${ }^{1}$ \\ Zeidi Araujo Trindade ${ }^{2}$ \\ Maria Cristina Smith Menandro 3
}

\begin{abstract}
RESUMO: O discurso do líder religioso articula-se como constructo que busca sintetizar a doutrina, a moralidade e a identidade grupal a que se destina a mensagem, assim como pode objetivar congregar novos fiéis ou mesmo neutralizar adversários. Este artigo analisou o discurso de Edir Macedo com o objetivo de compreender as representações sociais de cristão dele derivadas, por meio de duas corpora textuais: O jornal Folha Universal $(n=62)$ e o blog oficial do bispo ( $n=62$ ). Por intermédio da Teoria das Representações Sociais, da Análise de Conteúdo e com o auxílio dos softwares Alceste e Iramuteq foram analisados períodos e estratégias discursivas diferentes. Percebeu-se, em conclusão, a adequação do discurso religioso às três categorias propostas por Moscovici quando do trânsito das Representações Sociais: Propagação, Difusão e Propaganda.
\end{abstract}

Palavras-chave: representações sociais; religião; Edir Macedo; discurso; Igreja Universal.

\begin{abstract}
The religious leader speech is articulated as construct that seeks to synthesize the doctrine, morality and the group identity to which the message is addressed, as well as it could be aimed to congregate new faithful or even to counteract opponents. This article analyzed the Edir Macedo' speech in order to understand the social representations of christian derived from it, through two textual corpora: The Folha Universal newspapper $(n=62)$ and the Bishop's official blog ( $n=62)$. Through the Social Representations Theory, the Content Analysis and with the aid of Alceste and Iramuteq software, different periods and discursive strategies were analyzed. In conclusion, it was realized that the appropriateness of the religious speech to three categories proposed by Moscovici as the transit of the Social Representations: spread, difusion and advertising.
\end{abstract}

Keywords: social representations; religion; Edir Macedo; speech; the Universal Church.

\section{Introdução}

A religiosidade tem sido desde a gênese da constituição simbólica humana um mecanismo que pressupõe, não apenas crença, mas aspectos de dominação e de formação identitária. O ser humano sempre utilizou o ente divino como mediação explicativa entre o universo imaginário e o seu fazer no mundo. Mediação entre os elementos que não conseguia compreender e os aspectos políticos, sociais e econômicos, o que implicava a necessidade de um a priori de legalidade que sustentasse a racionalidade do grupo. Pensar a religiosidade deste modo transcende uma cosmovisão pautada no plano iluminista da

\footnotetext{
${ }^{1}$ Doutor em Psicologia pela Universidade Federal do Espírito Santo e Professor do Instituto Federal de Educação, Ciência e Tecnologia do Espírito Santo - Vila Velha, ES, Brasil. E-mail: diemersons@ifes.edu.br

2 Doutora em Psicologia pela Universidade de São Paulo (USP) e Professora da Universidade Federal do Espírito Santo Vitória, ES, Brasil.

${ }^{3}$ Doutora em Psicologia pela Universidade Federal do Espírito Santo e Professora da Universidade Federal do Espírito Santo - Vitória, ES, Brasil.
} 
teologia natural. Pensar a religiosidade implica pensar um ontos e um ethos social, diga-se ainda, pensar as representações sociais que os sujeitos religiosos articulam na constituição de suas identidades como elementos de um grupo com o qual partilham códigos, gestos e a própria vida em sociedade.

A pretensa secularização não extinguiu a experiência religiosa, mas pelo contrário tornou-a mais forte em suas metamorfoses, pois alterou a atuação eclesiológica, em experiências míticas e místicas mais potentes. Os aspectos litúrgicos, mesmo embebidos de meios de comunicação modernos, tem aparência mais primitiva, enquanto o sentimento de pertença social tornou-se mais aguerrido, quando associado a uma identidade religiosa, gerando, por vezes, um conjunto de críticas às muitas experiências fundamentalistas e violentas. O imaginário religioso, desta forma, tem povoado o mundo-da-vida e, assim, a identidade e as representações dos mais variados objetos sociais.

A religião acaba por funcionar como um "lugar" de compartilhamento de sentido, ainda que sincrético e pluralista. Percebe-se claramente esse aspecto quando se remonta aos aspectos linguísticos presentes nos discursos de líderes religiosos, nos meios de comunicação como o rádio, a televisão, o jornal e a internet.

Pensando o que se passa em países mais desarticulados economicamente, como os terceiro-mundistas, em que a pobreza e a marginalização dos meios produtivos tornam mais ativados os artefatos de sentido, compreende-se que existe um universo explosivo de símbolos religiosos que se interpõem à realidade social e política, em especial em regiões em que a secularização é frágil. O modo de produção capitalista, quando bem articulado, possibilita a migração do imaginário religioso para a ordem de consumo. A religião tende a ser mais forte quando em ausência de condições econômicas favoráveis (Lehmann, 2007, p. 69), o que implica afirmar que em condições de crises econômicas e sociais, a religião tende a se tornar um mecanismo mais atuante de estruturação psicossocial.

Obviamente não se está conferindo à pobreza a falta de sentido social ou cultural, mas aspectos mais carentes de apropriação de sentido são elaborados na desarticulação que a violência, a fome e certa anomia produzem. A religião oferece assim, um espaço de construção simbólica que congrega, pelo divino, a ideologia que atende as necessidades de seus fiéis. O discurso torna-se lei, modus vivendi, hermenêutica existencial, fórmula, enfim, os núcleos representacionais que orientam a construção identitária, que vê salvação naquilo que, de outra forma, poderia culminar em desalento.

A partir dessas premissas se pretendeu investigar as representações sociais de cristão comunicadas e culminadas nos discursos do bispo Edir Macedo, líder e fundador da Igreja Universal do Reino de Deus, IURD, em suas mensagens do Jornal Folha Universal, de circulação nacional, assim como nas mensagens publicadas em seu blog oficial.

Pensando com Moscovici (1990), que as relações sociais estão profundamente ligadas com transformações no pensamento, e compreendendo que este seja o veículo do fenômeno estudado, utilizou-se nessa pesquisa a Teoria das Representações Sociais, uma vez que o objeto de análise se constituía como representações de um líder religioso que compartilha a cognição, a afetividade e a identidade grupal.

As representações sociais são crenças, imagens e símbolos partilhados pelo grupo; são conceitos imbuídos de sentido gestores e gerados do/no compartilhamento do cotidiano, organizando a realidade e a prática social, ou, como define Cabecinhas (2004, p. 126): “As 
representações sócias estão ligadas a sistemas de pensamento mais largos, ideológicos ou culturais, e a um estado de conhecimentos científicos. As instâncias institucionais, os meios de comunicação mediáticos ou informais intervêm na sua elaboração, por meio de influência social". Jodelet (1984) chamou as representações sociais de "crivo de leitura" e é justamente neste sentido que se estabelece a importância das análises dos discursos dos líderes, religiosos ou não, pois é deste espaço de poder que a influência social é mais potente.

As relações entre o sujeito e o objeto estão em associação contínua com as práticas e simbolizações do sujeito (Sá, 1998). O sujeito deve às suas representações sociais a constante reconstrução da realidade, possível na doação de sentido, da interpretação e construção do mundo que o envolve (Jovchelovitch, 2000, p. 41).

O objeto, que é partilhado por um grupo socialmente, confere sentido às vidas em seus manejos coletivos e individuais, e tal sentido não se dissocia das práticas que também são partilhadas, conferindo assim a manutenção identitária de tais grupos (Trindade, Nascimento \& Gianórdoli-Nascimento, 2006, p. 190).

Outra perspectiva das representações sociais interessante à análise do fenômeno da religião é a consciência de que o discurso religioso por sua estabilidade, potência cognitiva/efetiva e ideias largamente compartilhadas e estruturadas, pode ser compreendido como um fenômeno que gera representações sociais hegemônicas. Conforme presente em Vala e Monteiro (2006) a hegemonia de uma representação se dá quando esta é "uniforme", "indiscutível" e "coercitiva".

Os estudos sobre a Igreja Universal do Reino de Deus (IURD) cresceram na seara da sociologia, como os de Gomes (2011), que apresenta uma perspectiva etnográfica dos espetáculos litúrgicos, e o de Teixeira (2014), que analisa as relações entre gênero e mídia dentro do neopentecostalismo iurdiano. Poucos, no entanto, se debruçam sobre o projeto pastoral de Edir Macedo, como ocorre com Mafra, Swatowiski e Sampaio (2012), ou sobre o próprio discurso do líder iurdiano, como em Swatowiski (2007).

A Psicologia, em especial a Psicologia Social, pouco tem investido em uma análise do fenômeno religioso como objeto de pesquisa. Paiva et al. (2009) realizaram diagnóstico com a análise de 125 obras que relacionam Psicologia e Religião, e verificaram que são raros os estudos de Psicologia Social sobre o assunto. É neste contexto que se apresenta essa pesquisa.

\section{Método}

O primeiro conjunto de dados foi coletado de 62 exemplares impressos do jornal Folha Universal (edições: 850 - 20/julho/2008 a 911 - 20/setembro/2009), um dos meios de comunicação da Igreja Universal do Reino de Deus, igreja neopentecostal fundada no Brasil, que têm ampla divulgação midiática. Utilizou-se a sessão "Mensagens" na qual Edir Macedo se pronunciava sobre os mais variados temas.

Os textos retirados do jornal Folha Universal foram submetidos integralmente ao software Alceste, que é um programa de análise de dados textual. Dessa forma palavras e expressões foram organizadas de acordo com sua importância semântica, de modo que fossem identificadas as categorias analisáveis dos textos do jornal. Em seguida utilizou-se, para a categorização dos eixos e classes identificados pelo Alceste, os critérios estabelecidos 
por Bardin (1977) de Análise de Conteúdo, na busca da promoção de sentido que permitisse uma análise mais acurada dos dados obtidos.

O segundo conjunto de dados foi coletado no blog oficial de Edir Macedo (http://blogs.universal.org/bispomacedo) no período de 29 de agosto a 25 de novembro de 2015. Como as postagens no blog são quase diárias, optou-se pelo seccionamento de 62 postagens para promover um equilíbrio entre os dois conjuntos de dados. A análise desse segundo conjunto utilizou o software Iramuteq, programa de análise de dados textual similar ao Alceste (ambos utilizam o Método Reinert), em função da dificuldade de acesso ao Alceste, assim como foram similares também os demais procedimentos de análise. 0 método, desse modo, buscou articular análise lexical e análise de conteúdo (Nascimento \& Menandro, 2006), utilizando as perspectivas de Ratinaud (2009), Reinert (1990) e Nascimento-Schulze e Camargo (2000).

Por fim, foram utilizados outros textos de líderes religiosos, como Macedo ${ }^{4}$ e Soares ${ }^{5}$, com a finalidade de ilustrar as imagens representacionais contidas nos dados.

\section{Resultados}

\section{Descrevendo classes}

O corpus de análise da sessão "Mensagem" do Bispo Edir Macedo, possuía 62 UCls (unidades de contexto inicial) que correspondem às divisões primárias dos textos analisados, que, no presente caso, seria o número de edições do Jornal Folha Universal. O corpus dessas $62 \mathrm{UCls}$ apresentou $375 \mathrm{UCEs}$ (unidades de contexto elementar) que seriam justamente as ideias frasais, com 70,97\% de material textual analisado, o que indica consistência razoável. Ressalta-se que a veracidade moral do discurso não é aqui discutida, pois um discurso mesmo que falacioso pode apresentar consistência, parâmetro indicado pela quantidade de material analisado pelo software.

As UCEs são associadas a uma ou outra classe em decorrência de uma medida de grau de associação que considera coocorrências (Qui-quadrado $-X^{2}$ ). A análise destas classes se dá por meio de uma Classificação Hierárquica Descendente (CHD) (Cortez \& Souza, 2008; Nascimento \& Menandro, 2006) que especifica a classificação do vocabulário, com sua frequência e força de relação. Os valores de $X^{2}$ de coocorrências de cada palavra sinalizam a sua importância semântica dentro de cada classe. Este mecanismo classificatório permite a caracterização dos núcleos representativos em dendrogramas, como o que está apresentado abaixo. Tais núcleos estão relacionados por coeficientes de compartilhamento de elementos (r), possibilitando as nomeações de classes e eixos e a discussão baseada nas suas relações.

\footnotetext{
${ }^{4}$ Macedo, E.B. (1990). Vida com Abundância. Rio de Janeiro, Universal Produções.

${ }^{5}$ Soares, R.R. (1985). As bênçãos que enriquecem. Rio de Janeiro, Graça Editoria.
} 


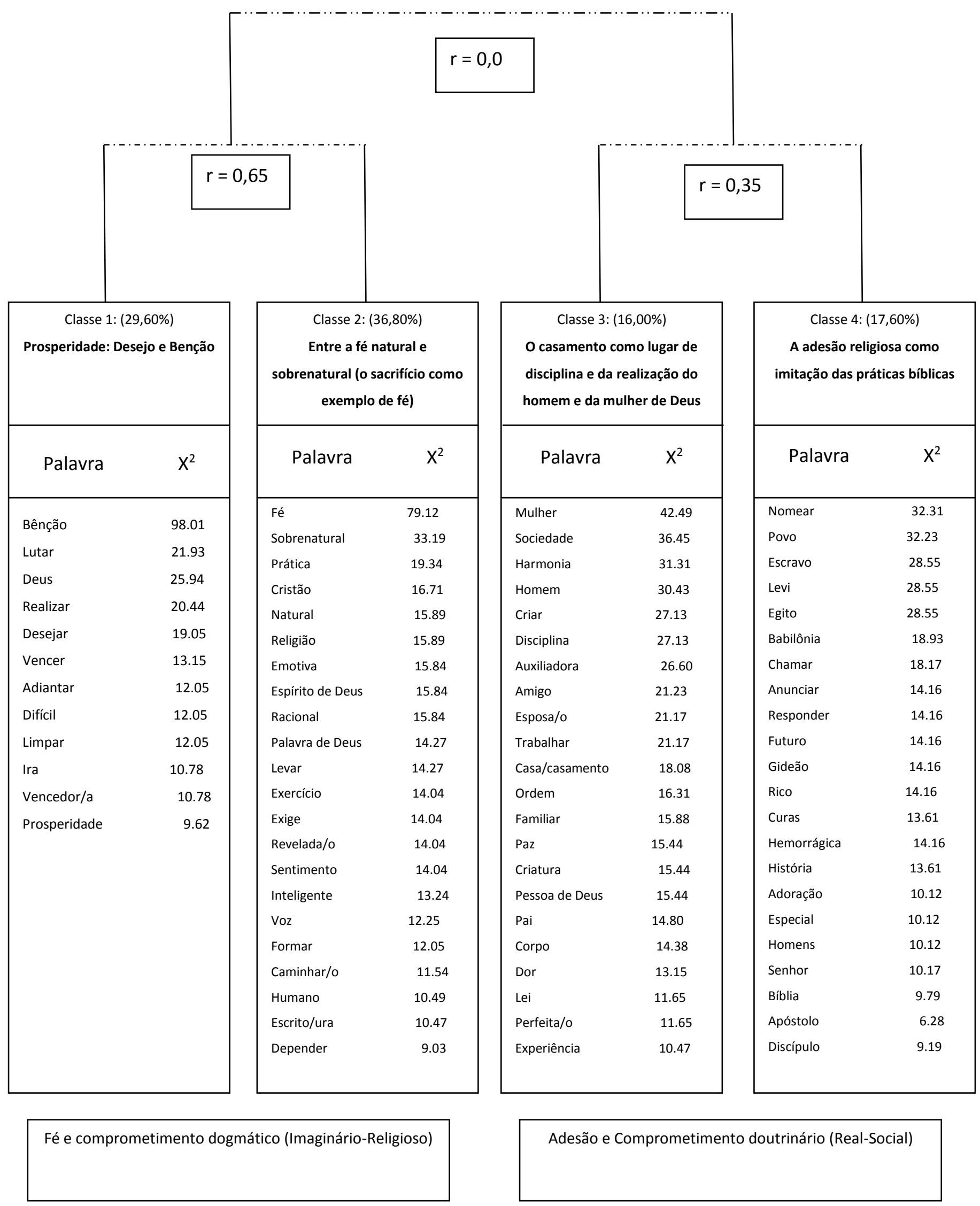

Figura 1 - Dendrograma do corpus lexical da sessão Mensagem do Bispo Macedo (2008/2009) 
A CHD dos discursos do bispo Edir Macedo na Folha Universal permitiu identificar 4 classes, subdivididas em dois eixos, que caracterizam o cristão. A classe 1, com 111 UCEs, denominada Prosperidade: Desejo e Bênção, apresentou aspectos relacionados a um dos eixos centrais da teologia neopentecostal, ou seja, a Teologia da Prosperidade. A classe 2, com 138 UCEs, denominada Entre a fé natural e sobrenatural (o sacrifício como exemplo de fé), foi a classe constituída com maior número de elementos e que apresentou relação forte com a classe $1(r=0,65 \%)$ em termos de compartilhamento de elementos. A fé sobrenatural é aquela associada diretamente com a promoção de milagres, e estimula a criação de vínculos com o sagrado, em liturgias que exigem a adesão do fiel à religiosidade por meio de sacrifícios, em especial o econômico, possibilitado pelo dízimo. Estas duas classes formam o eixo teológico apresentado pela eclesiologia iurdiana denominada: Fé e comprometimento dogmático (Imaginário-Religioso), pois cria os laços doutrinários que conferem a adesão religiosa.

O segundo eixo não apresenta relação com o primeiro, pois mesmo manifestando a forma como a doutrina se concretiza no real, marca a cisão entre o imaginário-alma e realcomportamento-corpo. O segundo eixo denominado: Adesão e Comprometimento doutrinário (Real-Social) apresenta o segundo braço iurdiano, ou seja, a nova modalidade neopentecostal de atuação, ostensiva nos fiéis adeptos. São os usos e os costumes que evidenciam a conversão pelo trato familiar e pela relação do real com as práticas bíblicas. A classe 3, com 60 UCEs, denominada $O$ casamento como lugar de disciplina e da realização do homem e da mulher de Deus, mostra a família como unidade eclesial básica, que pede aos fiéis um projeto de conformação estrutural que liga marido e esposa como continuidade das práticas desenvolvidas na igreja, como a disciplina. A classe 4, com 66 UCEs, denominada $A$ adesão religiosa como imitação das práticas bíblicas, mostra o conteúdo de embasamento bíblico que referencia e torna inquestionáveis os argumentos religiosos, naquilo que seria o projeto de salvação simbólico e tornado real pela adesão. Não se trata, pois de uma virtuose sem embasamento, mas a criação de laços com o divino que de fato congregam a vida dos sujeitos religiosos à religião possui um material de referenciação: o bíblico. $O$ imaginário passa a ter uma atuação no real e a teologia dogmática torna-se doutrina ou prática existencial. O sujeito confere o sentido da sua vida, com base nos artefatos religiosos, construindo sua identidade e interpretando o mundo com uma leitura representacional alinhavada ao religioso.

Segue-se o Dendrograma do corpus lexical do blog oficial do Bispo Macedo (2015) gerado pelo Iramuteq, com as nomeações das classes e eixos, assim como as palavras que compõem seus núcleos e os valores de qui-quadrado de cada palavra $\left(\mathrm{X}^{2}\right)$ que sinalizam a sua importância semântica dentro de cada classe: 


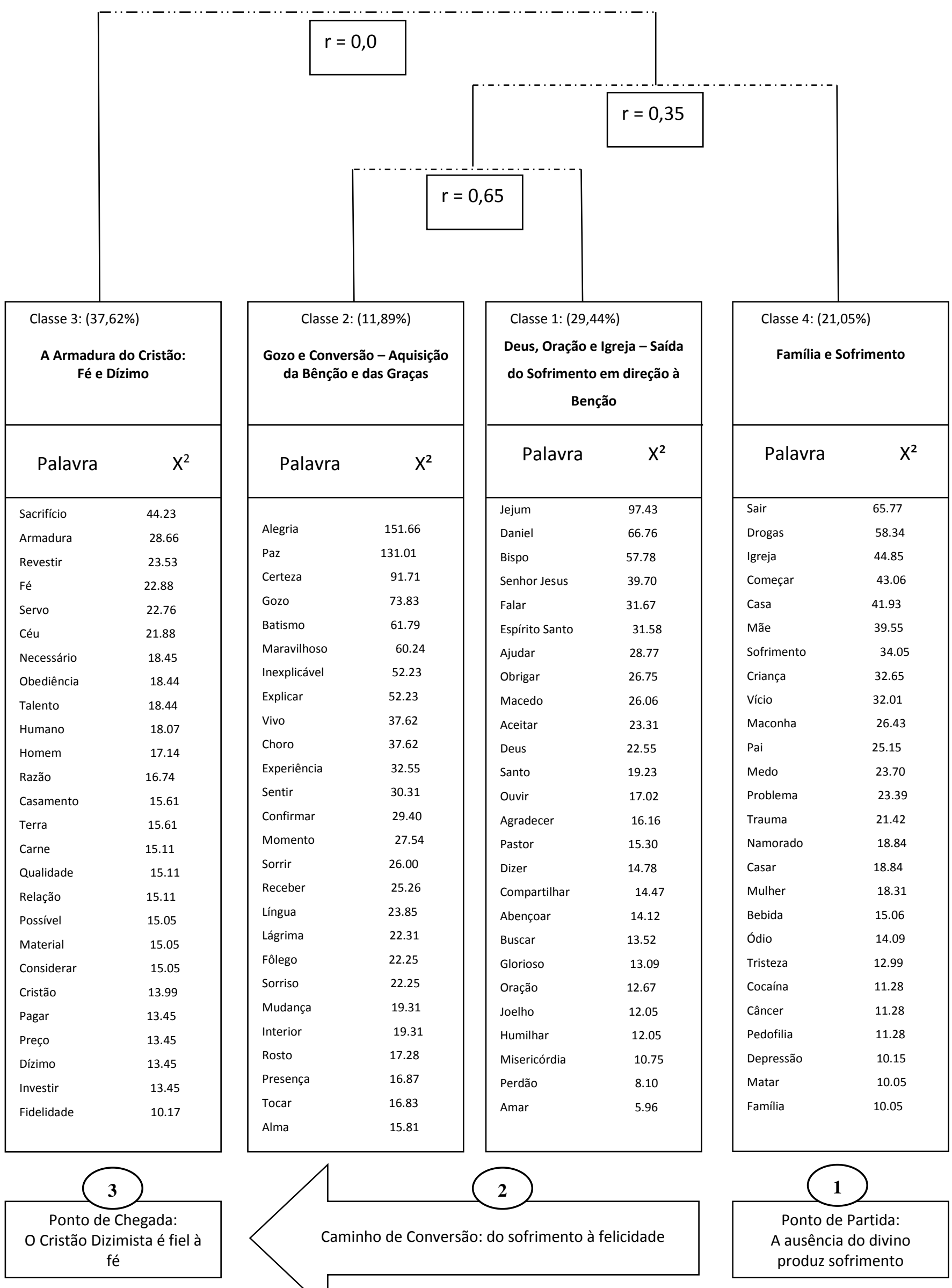

Figura 2 - Dendrograma do corpus lexical do blog oficial do Bispo Macedo (2015) 
A segunda análise lexical, também com 62 UCl's, agora com o corpus construído a partir de postagens do líder da IURD em seu blog oficial, teve $84,24 \%$ de construções frasais analisadas e organizadas em 1026 UCE's. A CHD dos discursos do bispo Edir Macedo em seu blog permitiu a identificação de 4 classes, subdivididas em três eixos, nas quais também se pode identificar a representação de cristão. O Eixo 1 (Ponto de Partida: A ausência do divino produz sofrimento) coincidente com a Classe 4, denominada de Família e Sofrimento, apresentou 216 UCE's ou 21,05\% do total do corpus lexical analisado. O Eixo 2 (Caminho de Conversão: do sofrimento à felicidade), possui em sua conjuntura as classes 1 e 2, constituindo-se as mais próximas. A classe 1, com 302 UCE's, foi denominada de Deus, Oração e lgreja - Saída do Sofrimento em direção à Benção. A classe 2, com 122 UCE's, foi denominada Gozo e Conversão - Aquisição da Bênção e das Graças. Por fim o Eixo 3 é o Ponto de Chegada e representa o cristão convertido que se assume pela fé e compromete-se na fidelidade do dízimo. Apenas uma classe constitui esse eixo, a classe 3, com 386 UCE's, denominada A Armadura do Cristão: Fé e Dízimo.

A dinâmica dos eixos obedece certa estrutura de caminho: antes da Igreja o sujeito não convertido possui todos os tipos de problemas e a família é desestruturada, é o momento do sofrimento. $\mathrm{O}$ sujeito então começa a orar, a frequentar a igreja, a expiar seus pecados (classe 1) até que alcança o gozo, a alegria, a cura (classe 2). De posse dessas bênçãos uma nova criatura é evocada, no eixo 3, que passa a ser fiel a Deus, à sua fé, à sua Igreja, e deve doar-se, também pelo dízimo, para assumir sua nova condição.

Os meios de comunicação permitem a passagem da linguagem a um estatuto de convencimento maior. Não se trata, pois de uma "Mensagem", ou de um anúncio despretensioso no blog, mas de um convencimento, de uma doutrinação, de uma ordem de sentido que dá ao sujeito um lugar e uma leitura de mundo no mundo.

\section{Discussão}

\section{Do Jornal Folha Universal ao Blog}

O Eixo I, Fé e Comprometimento Dogmático (Imaginário-Religioso) e suas classes, 1. Prosperidade: Desejo e Bênção e 2. Entre a fé natural e sobrenatural (o sacrifício como exemplo de fé) do primeiro dendrograma possui estreitas relações com todo o conjunto do segundo corpus lexical que organiza as mensagens do blog oficial de Edir Macedo.

As classes 1 e 2 (do corpus do Jornal) estão muito próximas e ambas apresentam a ritualista dogmática que articula uma maneira de perceber a fé e como essa se relaciona às bênçãos recebidas pelos fiéis. $O$ deleite prometido aos pobres e aos afortunados torna-se vinculado à generosidade que o homem deve copiar do Pai. Uma temática universal em todos os mecanismos religiosos é a do sofrimento e dos infortúnios que acabam por gerar degradação, miséria e morte. Como promessa, o que advém é uma doutrina da salvação, uma libertação das tantas chagas sofridas. Mensagem querida às massas que necessitam de consolo e de esperança. O pentecostalismo durante muito tempo esteve alheio ao empreendimento proselitista que o uso dessa mensagem poderia permitir e, por intermédio de uma forte tendência sectarista e ascética, pregava a desvalorização do mundo. Este mundo corrupto pertencente à matéria seria facilmente manipulável por Satanás, portanto, repudiado, uma vez que a Salvação tinha como local de realização o Paraíso Celeste. Tal 
asceticismo era praticável sem grandes tensões quando pregado a uma população já privada de bens de consumo ditos "mundanos".

Eis o Eixo 1 do segundo corpus: Na ausência do divino, o sujeito no mundo, é ladeado de todos os sofrimentos e vícios. Maconha, medo, problemas, traumas, bebidas, ódio, tristeza, cocaína, câncer, pedofilia, depressão e matar, são exemplos de sofrimentos apontados na classe 4 e estão associados à necessidade expiação, presente na classe 1, em que o sujeito se aproximando da igreja e de Deus, deve abandonar o "homem velho", realizar o "jejum de Daniel", e converter-se.

Com o crescimento econômico do país, hoje já em declínio, uma parcela de brasileiros passou a usufruir de uma mobilidade social nunca dantes experimentada. $O$ sacrifício alcançava, então, outra tonalidade, visto que a sociedade de consumo, e todos os apelos aí locados, persistiam na alteração tipológica do discurso, abrindo o religioso aos deleites materiais. O mundano devia ser acomodado, ancorado e objetivado, possibilitando um processo gradual de sacralização do secular, de aceitação do consumo. E esta modalidade de pertença social começa a criar feições dentro do mundo pentecostal.

Os anos de 1970 abriam espaço para o neopentecostalismo e, com ele, para a Teologia da Prosperidade, que tem origem nos EUA dos anos de 1940, mas tornou-se doutrina apenas nos anos de 1970. A riqueza, condição avessa à participação no Reino, almejada como que em uma segunda doutrina calvinista neo-burguesa, agora já capitalista, passa a compor o cenário dos ditos eleitos e amados de Deus. Ricardo Mariano afirma a respeito:

Com promessas de que o mundo seria locus de felicidade, prosperidade e abundância de vida para os cristãos, herdeiros das promessas divinas, a Teologia da Prosperidade veio coroar e impulsionar a incipiente tendência de acomodação ao mundo de várias igrejas pentecostais aos valores e interesses do 'mundo', isto é, à sociedade de consumo (Mariano, 1999, p. 149).

As mudanças são, portanto, o esmorecimento do discurso escatológico diante da inadaptação do crente ao mundo, do sectarismo e do asceticismo que abrem, por sua vez, o evangélico à participação política, à educação formal, à busca de riqueza e de liberdade na escolha de uma determinada profissão: o esporte, a música, tudo isso sem ferir a moral. A mídia televisiva é, e desde o início foi, o mecanismo mais utilizado para a propagação das doutrinas da prosperidade, ainda que a internet tenha aparecido como importante meio de propagação da mensagem da prosperidade. Nelas o cristão tem poder de fazer existir o que com fé proclama: estão disponíveis nesta vida a saúde e a riqueza (Barron, 1987). Esses elementos estão presentes no Eixo 3 que, inclusive, representa a maior parte do conjunto de UCE's da análise lexical do blog: O dízimo como representação da fé, pois é representação da passagem de uma fé natural-emocional para uma fé racional-sobrenatural.

A fé, elemento fundamental da doutrina cristã protestante, em aposição à dualidade católica de fé e obras, torna-se o principal emblema ou a chave para tudo se alcançar. Mariano lista as bênçãos mais declaradas: "Saúde perfeita, ou cura de enfermidades, prosperidade material, triunfo sobre o Diabo, uma vida plena de vitória e felicidades, 'direitos' do cristão, anunciados na Bíblia, figuram entre as bênçãos mais declaradas por eles" (Mariano, 1999, p.154). Tudo embasado num "princípio de reciprocidade" citado por Mauss (1974) em que o cristão deve decretar e exigir em nome de Deus e ao mesmo tempo também fazer sacrifícios e ser fiel como demonstração de verdadeira entrega e confiança em nome desta fé. Toma-se, desta forma, posse das graças, mesmo antes destas terem sido alcançadas. 
O vocabulário apresentado na primeira classe mostra que é fundamental no discurso do bispo Edir Macedo essa relação entre benção e enfrentamento do fracasso e do desânimo como pontos de aquisição de prosperidade. Com uma relação de força de associação à classe muito forte $\left(X^{2}=98,01\right)$ a "benção" parece ser o ponto fundamental do alinhamento do desejo às crenças.

Note-se como a perspectiva teológica da luta pela benção é caracterizada nas UCEs ${ }^{6}$ :

Difícil é manter-se salvo. Que tipo de luta a pessoa deve travar para tornar-se vencedora aos olhos do Senhor Jesus Cristo? A luta contra as inclinações da carne ou de realizar a própria vontade.

Não adianta a pessoa ter fé durante uma reunião na igreja, se não souber resistir às preocupações e a ansiedade. Não adianta orar, clamar, suplicar, é preciso manter a fé no auge, pois só conquistamos através dela.

À cruz, ao sacrifício e ao martírio, temas clássicos do cristianismo, aos poucos vem se apresentando uma nova ordem, um novo sistema axiológico. Não se quer mais o Cristo da Cruz, mas a mensagem de salvação. A Ressurreição, a Vitória e o que seriam estas manifestações hoje, na realidade material, são procuradas como fonte para alcançar saúde, riqueza, felicidade, poder e sucesso.

Mas todas as graças necessitam que o indivíduo restabeleça a aliança com Deus, quebrada pelo pecado. E a chave que religa e permite uma nova aliança entre o humano e o Senhor não é outra senão a fidelidade ao pagamento do dízimo, que Edir Macedo chamará de "o sangue da Igreja". Desta forma o humano restabelece a aliança antes quebrada pelo mal e volta a ser herdeiro das benesses celestes possíveis de se tornarem realidade nesta vida, ou seja, a "vida abundante", seguindo o termo de Oral Roberts (2016).

Edir Macedo, ao falar sobre o dízimo, utiliza estes termos:

Ele [Jesus] desfez as barreiras que havia entre você e Deus e agora diz - volte para casa, para o Jardim da Abundância para o qual você foi criado. E viva a Vida Abundante que Deus amorosamente deseja para você (...) Deus deseja ser nosso sócio (...). As bases de nossa sociedade com Deus são as seguintes: o que nos pertence (nossa vida, nossa força, nosso dinheiro) passa a pertencer a Deus; e o que é d’Ele (as bênçãos, a paz, a felicidade, a alegria, e tudo de bom) passa a nos pertencer (Macedo, 1990, pp. 25, 85, 86).

A onipotência de Deus é quebrada, uma vez que, associado a um contrato, não pode se furtar a conceder as bênçãos de que o fiel se faz donatário: "Nós ensinamos as pessoas a cobrar de Deus aquilo que está escrito. Se Ele não responder, a pessoa tem de exigir, bater o pé, dizer 'tô aqui, tô precisando'" (Macedo, Folha de São Paulo, 20.06.1991). Esse ensinamento está presente no Eixo 2 do corpus das postagens do blog. O sujeito deve orar, incessantemente, para superar os infortúnios e alcançar o gozo e as alegrias (classe 2).

Os fiéis, além do dízimo, são incentivados a trabalharem muito, a serem inteligentes e a terem espírito empreendedor. Da mesma forma que a Universal do Reino de Deus, Internacional da Graça, Renascer em Cristo e Sara Nossa Terra promovem encontros de empreendedores e empresários motivando-os a participar de correntes, como as "correntes da ambição" promovidas pela Universal. Desta forma estes empresários associam suas empresas ao sistema religioso e partilham seus lucros com a igreja, como sinal da prosperidade que Deus lhes concede.

\footnotetext{
${ }^{6}$ Todas as UCEs (Unidades de Contexto Elementar) que serão apresentadas se referem a trechos do discurso de Edir Macedo.
} 
Todavia, a severidade na cobrança de dízimos também está presente em outras igrejas pentecostais. Os membros da Casa da Bênção que não estão com o dízimo de $15 \%$ da renda em dia têm seus nomes expostos; os membros da Igreja Deus é Amor que não estão em dia com o pagamento do dízimo não podem comungar da Ceia do Senhor, condição para a Salvação. Habilitam-se apenas aqueles que apresentarem aos obreiros o cartão do dízimo devidamente quitado. A Igreja Universal de Belo Horizonte, segundo o jornal $O$ Globo de 16.08.1992, chegou a cobrar $30 \%$ da renda do fiel, alegando que a Trindade partilharia: $10 \%$ para o Pai, $10 \%$ para o filho e $10 \%$ para o Espírito Santo.

As inovações continuam: existem correntes da prosperidade; fogueiras santas, nas quais pedidos (nunca as ofertas) são queimados; e até distribuição de brindes. Mas algo é sempre uma constante: as bênçãos prometidas sempre estão intimamente ligadas ao dízimo e às ofertas e lhes são proporcionais. $O$ dízimo no sacrifício é prova de fé.

Diante de todos esses estímulos de ordem eclesiológica e comportamental, abrem-se discussões sobre o conteúdo ético deste mecanismo teológico, o da prosperidade, associando dinheiro, religião e política. 0 vocabulário da classe 2 deixa clara a relação entre a fé e aquilo que é extraordinário, o que provocaria a eliminação das dúvidas do fiel: a pessoa racionaliza a fé, tornando-a uma certeza, e assim passa a exercê-la no mundo.

A classe 2, do primeiro dendrograma, não apresenta o termo "dízimo", mas deixa clara a relação existente entre a doação de quantias, a fidelidade e a fé sobrenatural. $O$ termo dízimo, no entanto, aparece na classe 3 , do segundo dendrograma, em mesmo contexto. $A$ fé sobrenatural e, portanto, racionalizada e inteligente, segundo os discursos analisados, impõe uma relação exigente ao fiel que deseja ligar-se a Deus de alguma maneira. A conquista de benefícios é, assim, uma relação mercadológica que se estabelece com o divino, não se tratando apenas da salvação, mas de tudo que uma ligação desta natureza permitiria. E ao fiel restaria, para sustentar tal modalidade de fé, a conversão e, como consequência, a oferta.

Algumas UCEs apresentam a fé entendida como ligada às práticas de relacionamento pessoal com o divino.

\begin{abstract}
A revelação da fé. Nada nem ninguém é mais importante que a fé sobrenatural revelada pelo espírito de Deus ao ser humano. Tão enorme é a importância dela que a bíblia não apenas a coloca como única ponte de ligação com Deus, mas como única ferramenta de salvação eterna: o justo viverá pela sua fé. Habacuque 2.

Esse tipo de pessoa é a que não tem nem coragem de sacrificar a vida pela salvação, quanto mais para conquistar benefícios. Antes, são indivíduos covardes e sujeitos às circunstâncias adversas. Porém, o mesmo não acontece quando a fé é separada da emoção.
\end{abstract}

Apresenta-se, desta forma, um discurso claramente doutrinador, mesmo que em alguns momentos velado pelo uso variado de sinônimos eufêmicos. Edir Macedo apresenta, então, a necessidade da fé e da bênção como elementos centrais, nucleares do jogo representacional teológico.

O Eixo II, Adesão e Comprometimento doutrinário (Real-Social), e a classe 3: O casamento como lugar de disciplina e da realização do homem e da mulher de Deus, do primeiro dendrograma, tem elementos repetidos na classe 4 do segundo dendrograma.

A terceira classe, no corpus do jornal, tem um público mais específico de acesso: as famílias. Em especial as mulheres congregadas, chamadas à responsabilidade de converter seus maridos e de manter, além da harmonia da casa, um lugar de submissão. O espaço 
religioso, tradicionalmente mais associado ao universo feminino e à casa, toma clara feição no discurso neopentecostal. Está a cargo da mulher sábia a construção de uma relação perfeita com seu marido.

Não há a mínima chance de felicidade sem a perfeita harmonia entre marido e mulher, cabeça e corpo. A construção dessa relação perfeita está justamente a cargo da mulher sábia.

A boa relação com Deus, então, é naturalizada no relacionamento conjugal. Mesmo o exercício da sexualidade é apontado por Macedo como um gesto que congrega não somente o marido à mulher, mas Deus ao homem.

Este é, justamente, o mundo em que vivemos. Um lugar onde não há harmonia entre criador, criatura e natureza, daí a violência desencadeada e desenfreada. O relacionamento conjugal é tão sagrado que simboliza a aliança do criador com a criatura. $\mathrm{O}$ ato da penetração faz com que homem e mulher se tornem uma só carne.

Homem e mulher, no entanto, estão hierarquicamente divididos, pois à mulher é conferido um lugar de submissão. Da mulher são exigidas a harmonia da casa, a manutenção da felicidade, a educação dos filhos, mas, a estas responsabilidades comuns a uma história feminina de pouca autonomia e liberdade, se soma, apoiada pela religiosidade, a caracterização da mulher apenas como o "pescoço" de sustentação das atividades do homem. À "cabeça", lugar típico do sexo masculino, está destinado o trabalho de sustentação da família, o poder de gerir e pensar a família.

Cada um tem seu papel importante na construção de uma sociedade perfeita. A cabeça, o homem, não pode dar nem um passo sem o corpo, a mulher.

O casamento, além da manutenção de seus lugares nucleares e historicamente defendidos pela religiosidade cristã, precisa de disciplina, segundo Edir Macedo, para que não seja associado à irracionalidade.

Neste contexto, há disciplina e desenvolvimento. E daí vem a harmonia entre criador, criatura e natureza, uma trindade sagrada e integrada. Porém, quando o relacionamento é meramente sexual, não há amor, nem responsabilidade. O conceito familiar inexiste, e o comportamento se torna similar ao dos animais irracionais.

A constituição familiar, no entanto, é claramente estabelecida entre homem e mulher, uma vez que a religiosidade é clara na recusa à homossexualidade.

Contudo, Deus criou a família, o casal. Ele não criou o homem e outro homem, a mulher e outra mulher, mas tão somente o homem e a mulher, o homem e sua auxiliadora.

Não há nenhuma perspectiva religiosa no cristianismo e, em especial, no neopentecostalismo, sem a devida justificativa bíblica. Comportamentos dos tipos considerados mais simples passam a possuir um vínculo com as alegorias bíblicas, mesmo que isso se dê em perspectiva atemporal.

A adoração de Deus e a justificativa criacionista:

Se assim o fosse, não teríamos maravilhas como um céu estrelado na noite de verão para contemplar, por exemplo. Quando a pessoa alcança esse entendimento espiritual, jamais se curva diante das obras das mãos dos homens, porque a adoração é focalizada apenas em um ser supremo e inteligente: Deus.

$\mathrm{O}$ arrependimento dos pecados:

E o pior é quando compartilham as recordações pecaminosas com outros. Agindo assim, provam a falta de arrependimento sincero dos erros passados. E aí está o principal motivo por que não conseguem a libertação imediata e muito menos o novo nascimento. $O$ arrependimento é a ordem do dia na bíblia sagrada. 
O segundo eixo do primeiro corpus apresenta comportamentos e posturas que devem possuir os fiéis. A família, questões de gênero, o posicionamento contrário à homossexualidade, e todas as práticas justificadas pelas leituras bíblicas apontam a centralidade da hermenêutica representacional de mundo dos fiéis pautadas por Edir Macedo, personificação da eclesiologia e assim da formação identitária dos membros religiosos.

Independentemente do meio de comunicação, se jornal ou blog de internet, o discurso de Edir Macedo é o discurso da IURD, com variações na disposição ou estratégias, mas de igual conteúdo. Trata-se um discurso de Propagação e de Propaganda.

O discurso de Edir Macedo, deste modo, possui a marca da hegemonia quando direcionada para seu grupo, com a forte influência social de ancoragens alicerçadas nas crenças e nos valores. Quando o discurso é direcionado a sujeitos que se compreendem cristãos, mas de outra vivência eclesiológica/doutrinária o discurso deixa de ser hegemônico e passa a ser concebido como originário de representações sociais polêmicas, porque discutíveis.

Ora com esta dupla característica discursiva, duas são também as estratégias que os atos comunicativos tomam: Propaganda e Propagação. Para entendermos estes termos moscovicianos utilizaremos o entendimento presente em Vala e Monteiro (2006) que definem propaganda como um discurso apresentado em contextos de mundo conflituosos e repleto de clivagens, ou seja, a mensagem para grupos diferentes, pela busca de certo convencimento e a aquisição do estatuto de verdade. A propagação, por sua vez tem por finalidade a integração de uma nova informação ou ainda o reforço da mesma no sistema de valores de um determinado grupo.

É possível pensar uma explicação para que as estratégias de comunicação religiosa atuem de modo tão incisivo nas mídias de massa. A mensagem do cristianismo (que seria entendida como uma oportunidade catequética e salvífica) é conduzida como propagação, como mensagem das igrejas para impor a sua verdade como propaganda. Nos dois casos a comunicação tem como base a representação social de cristão ideal.

Trata-se de um discurso intencional, por isso a impossibilidade de compreendê-lo como difusão. Vejamos as ideias de gênero e de casamento da Igreja Universal do Reino de Deus, elas aparecem repetidas em 198 postagens do blog de Edir Macedo, sendo a primeira ocorrida no dia 04 de janeiro de 2009, no texto intitulado: a Fé e o Sexo. O conteúdo é radicalmente o mesmo das Mensagens do Jornal Folha Universal. O mesmo ocorre com a ideia de prosperidade que se repete 30 vezes no blog ou dinheiro que se repete por 177 vezes a partir de 04 de março de 2009 com o texto "Questão de fé... relacionar pedidos de oração com ofertas?". Dízimo aparece com 99 ocorrências. Mas nada supera a Fé com 1817 ocorrências.

O discurso de Edir Macedo é a propagação da mensagem doutrinária aos membros de sua religião, os que devem se constituir em cristãos ideais. O discurso de Edir Macedo é a propaganda da mensagem claramente clivada e conflituosa, também na busca de novos fiéis.

A representação social de Cristão emergente dos discursos de Macedo cria a imagem do cristão ideal, e deste modo podemos ressaltar cinco elementos centrais: 
1) O cristão verdadeiro deve ser fiel à fé racional, ou seja, ultrapassar o sentido da crença dando-lhe estatuto de certeza e assim rompendo com o que é natural e alcançando o sobrenatural;

2) O cristão manifesta essa fé por intermédio da mudança radical de vida, mudando hábitos. Só assim é possível a passagem do universo mundano para o celeste, ou seja, a saída do mundo de sofrimentos e vícios em direção às bênçãos e virtudes;

3) O cristão deve assumir-se pela adesão às práticas reificadas no universo bíblico. O que está fora da bíblia não existe, pois, o cristão verdadeiro deve assumir a bíblia como verdade e referência absoluta de seu agir, pensar, sentir. Deste modo as imagens bíblicas são repetidas como referência ampliando a potência da influência social sob a qual se constrói o discurso da liderança religiosa;

4) A prosperidade é uma característica essencial da representação social de cristão. A separação entre o celeste e o terreno é definitivamente abolida, e as graças materiais devem ser alcançadas pelo fiel em vida. A metodologia de acesso a isto é a fé justificada pelo pagamento do dízimo, pela doação, pela entrega;

5) Por fim, a ideia de patriarcado é essencial para a construção da imagem representacional de cristão. $O$ homem deve ser heterossexual, moralizador, cabeça e por sua vez, deve subjugar a mulher, em defesa do casamento e da família cristã. A mulher deve reconhecer a liderança masculina e afeiçoar-se às obrigações matrimoniais e maternais, trata-se da imagem de corpo/pescoço, mas de fato, não é cabeça.

Tais aspectos apontam a necessidade de pesquisas psicossociais da religião, em especial as vinculadas à manifestação pública das ideologias religiosas nos meios de comunicação de massa. Não se trata tão somente do diagnóstico das relações de poder estabelecidas pelo mecanismo religioso, mas também a verificação das modalidades diversas de atuação identitária e das representações sociais dos sujeitos religiosos. Verificase uma necessidade crescente de sentido social. Investigar os discursos públicos de Edir Macedo evidenciou uma leitura de mundo, biblicamente justificada, de relacionamento com o sagrado pautado pela fé e pela bênção, em comportamentos expressos nos ambientes de convivência cotidiana, como o familiar que determina a natureza de vínculos que devem existir entre marido e esposa. A crença, na contemporaneidade cada vez mais midiatizada e apelativa, tem construído espaços de compreensão que se vinculam em laços que tramitam entre o aceitável e o injustificável, entre o saudável e o patológico, em especial em alguns espaços fundamentalistas.

\section{Referências}

Bardin, L. (1977). Análise de conteúdo. (L. Reto \& A. Pinheiro, Trad.). Lisboa: Edições 70.

Barron, B. (1987). The health and wealth Gospel: what's going on today in a movement that has shaped the faith of millions? Illinois: InterVarsity Press.

Cabecinhas, R. (2004). Representações sociais, relações intergrupais e cognição social. Paidéia, 14(28), 125-137.

Cortez, M.B. e Souza, L. (2008). Mulheres (in)Subordinadas: o Empoderamento Feminino e suas Repercussões nas Ocorrências de Violência Conjugal. Psicologia: Teoria e Pesquisa, 24(2), 171-180.

Gomes, E. de C. (2011). A era das catedrais: a autenticidade em exibição. Uma etnografia. Rio de Janeiro: Garamond. 
Jodelet, D. (1984). Représentation sociale: phenomènes, concept et théories. In: Moscovici, S. (Org). Psychologie sociale. Paris: PUF.

Jovchelovitch, S. (2000). Representações Sociais e Esfera Pública. Petrópolis, RJ: Vozes.

Lehmann, D. (2007). A milagrosa economia da religião: um ensaio sobre capital social. Horizontes Antropológicos, 13(27), 69-98.

Mafra, C.; Swatowiski, C. \& Sampaio, C. (2012). O projeto pastoral de Edir Macedo: uma igreja benevolente para indivíduos ambiciosos? Revista Brasileira de Ciências Sociais, 27(78), 81-96.

Mariano, R. (1999). Neopentecostais: sociologia do novo pentecostalismo no Brasil. SP: Loyola.

Mauss, M. (1974). Ensaio sobre a Dádiva, forma e razão da troca nas sociedades. In: M. Mauss. Sociologia e Antropologia, v.ll, São Paulo: Ática.

Moscovici, S. (1990). Social Psychology and Developmental Psychology: Extending the Conversation. In: Duveen, G. \& Lloyd, B. Social Representations and Development of Knowledg (pp. 164-185). Cambridge: Cambridge University Press.

Nascimento, A. R. A., \& Menandro, P. R. M. (2006). Análise lexical e análise de conteúdo: uma proposta de utilização conjugada. Estudos e Pesquisas em Psicologia, 6(2), 72-88.

Nascimento-Schulze, C. M., \& Camargo, B. V. (2000). Psicologia social, representações sociais e métodos. Temas de Psicologia, 8(3), 287-299.

Paiva, G. J. de, Zangari, W., Paula, J. R. M. de, Faria, D. G. R. de, Gomes, D. M., Fontes, F. C. C., Rodrigues, C. C. L., Trovato, M. L., \& Gomes, A. M. A. (2009). Psicologia da Religião no Brasil: a produção em periódicos e livros. Psicologia: Teoria e Pesquisa, 25(3), 441-446.

Ratinaud, P. (2009). Iramuteq: Interface de R pour les Analyses Multidimensionnelles de Textes et de Questionnaires [Computer software]. Retrieved from http://www.iramuteq.org.

Reinert, M. (1990). Alceste, une méthodologie d'analyse des données textuelles et une application: Aurélia de G. de Nerval. Bulletin de Méthodologie Sociologique, 26, 24-54.

Roberts, O. (2016). O Milagre da Semente da Fé. Rio de Janeiro: Graça Editorial.

Sá, C. P. (1998). A Construção do Objeto de Pesquisa em Representações Sociais. Rio de Janeiro: EdUERJ.

Swatowiski, C. W. (2007). Texto e contextos da fé: o discurso mediado de Edir Macedo. Religião \& Sociedade, $27(1), 114-131$.

Teixeira, J. M. (2014). Mídia e performances de gênero na Igreja Universal: O desafio Godllywood. Religião \& Sociedade, 34(2), 232-256.

Trindade, Z. A., Nascimento, A. R. A. \& Gianórdoli-Nascimento, I. F. (2006). Resistência e mudança: representações sociais de homens e mulheres ideais. In: Almeida, A. M. O.; Santos, M. F. S.; Diniz, G. R. S \& Trindade, Z. A. (Org.). Violência, exclusão social e desenvolvimento humano. Estudos em representações sociais (pp. 187-213), 1 ed. Brasília: Ed. UnB, v. 1.

Vala, J., \& Monteiro, M. (2006). Psicologia Social. 7ạ ed. Lisboa: Fundação Calouste Gulbenkian. 